\title{
Two Types of Resistance to the Diamondback Moth (Lepidoptera: Plutellidae) in Cabbage
}

\author{
SANFORD D. EIGENBRODE, ANTHONY M. SHELTON, \\ AND MICHAEL H. DICKSON ${ }^{1}$
}

\author{
Department of Entomology, New York State Agricultural Experiment Station, \\ Cornell University, Geneva, New York 14456
}

\begin{abstract}
Environ. Entomol. 19(4): 1086-1090 (1990)
ABSTRACT Survival of larvae of the diamondback moth, Plutella xylostella (L.) was reduced on several genotypes of cabbage from the breeding program at Geneva, N.Y. Polar fractions of ethanol extracts of partially resistant lines 2535 and 2503 , when incorporated into diet, reduced survival of $P$. xylostella larvae by 14.9 and $19.0 \%$, respectively. Whether this effect was due to reduced feeding or postingestive toxicity was not determined. Although survival on glossy-leafed line 2518 was very low in the field and larvae on this line failed to form visible feeding mines during the first $72 \mathrm{~h}$ after egg hatch, extracts from 2518 had no activity. Survival of larvae confined on leaf disks of 2518 in the laboratory was much greater ( $80 \%$ of controls) than it was on whole plants in the field $(0.36 \%$ of controls). In the field, neonate $P$. xylostella dispersed two to three times more rapidly on the leaves of 2518 than on other lines. Resistance to $P$. xylostella in the lines investigated was therefore due to at least two mechanisms, (1) antibiosis or nonpreference due to extractable compounds present in normal bloom resistant cabbage genotypes, 2503 and 2535, and (2) possible nonpreference for glossy-leafed 2518 by neonate larvae, as suggested by the greater dispersal rates of neonates on these plants. Survival is relatively high on 2518 in leaf disk bioassays in the laboratory, suggesting that nonpreference in combination with environmental stresses to larvae in the field may produce $P$. xylostella resistance in the glossy 2518 .
\end{abstract}

KEY WORDS Insecta, Plutella xylostella, cabbage, host plant resistance

THE DIAMONDBACK MOTH, Plutella xylostella (L.), is a serious pest of crucifer crops throughout the world. In a recent survey of insecticide resistance throughout North America, high levels of resistance to permethrin and methomyl were also found (unpublished data). Alternatives to chemical controls for $P$. xylostella are needed. One approach is the development of resistant cultivars. $P$. xylostella-resistant Brassica genotypes, developed at the New York State Agricultural Experiment Station, Geneva, include glossy-leafed types descended from the Australian cauliflower, PI 234599, as well as resistant genotypes with normal waxy bloom (Dickson \& Eckenrode 1980; Lin et al. 1983, 1984; unpublished data). Resistance to $P$. xylostella in glossy cabbage genotypes has been shown to be due to reduced survival of first instars (Lin et al. 1983). Survival of $P$. xylostella also differs among existing normal bloom cultivars (Lin et al. 1983, Shelton et al. 1988). The mechanisms that reduce larval survival and lead to the resistance in glossy-leafed and normal bloom cabbage are unknown. Knowledge of these mechanisms will increase the efficiency of the breeding program and improve our understanding of the interactions of this insect with its host plants.

\footnotetext{
' Department of Horticultural Science, New York State Agricultural Experimental Station, Cornell University, Geneva, N.Y. 14456.
}

Experiments were conducted to quantify levels of larval survival of $P$. xylostella on glossy and normal bloom resistant cabbage breeding lines. The chemical basis of the resistance was investigated by measuring larval survival on diet supplemented with extracts from resistant and susceptible plants. Finally, larval dispersal was observed on resistant and susceptible plants, and larval preferences were measured in choice experiments between genotypes with different levels of resistance.

\section{Materials and Methods}

Cabbage genotypes investigated were 2535 and 2518, normal bloom and glossy-leafed inbred lines, respectively, with PI 234599 in their parentage, and 2506 and 2503, normal bloom inbred lines unrelated to PI 234599. The susceptible cultivar, 'Round-Up,' was used as a control. In previous screening trials based on visual damage scores, these genotypes ranked, from most to least damaged: 'Round-Up' > 2506 > 2503 > 2535 > 2518 .

Plants were grown from seed in the greenhouse and transplanted into field plots 8 wk after germination. Each plot consisted of 36 plants in six rows. The spacing was $90 \mathrm{~cm}$ between rows and $45 \mathrm{~cm}$ between plants within rows. The plots were arranged in three randomized blocks. Identical plantings were made on 11 June and 8 July 1987 at the Vegetable Research Farm at the New York 
State Agricultural Experiment Station, near Geneva. From 6 wk after transplanting to heading stage, plants from these blocks were used for the tests described below as follows: rows one and two, whole-plant inoculations; row three, cage studies; row four, leaf disks; row five, extracts; row six, behavioral observations.

Plutella xylostella were obtained from a laboratory colony established from insects collected in commercial cabbage fields near Geneva, and maintained on artificial diet (Biever \& Boldt 1971; unpublished data). Eggs were collected from the colony on aluminum foil strips treated with cabbage extract.

\section{Larval Survival on Plants in the Field}

Whole-Plant Inoculations. Three plants per block were inoculated with $200 P$. xylostella eggs each by pinning aluminum foil with eggs to an upper frame leaf (Andaloro et al. 1983). When larvae reached fourth instar, the plants were destructively censused for larvae. Larval survival was estimated using a mean egg hatch rate of $51.8 \pm$ $4.3 \%$, obtained from a single sample of 30 similar aluminum foil sheets with eggs placed in the field. The plants in the first planting were inoculated on 24 July and evaluated on 5 August, those in the second planting were inoculated on 17 August and evaluated on 4 September.

Three additional plants per block for each line in the first planting were inoculated with 100 eggs per plant on $10 \mathrm{July.} \mathrm{The} \mathrm{number} \mathrm{of} \mathrm{mines} \mathrm{per}$ plant was counted $72 \mathrm{~h}$ after the eggs hatched.

Cage Studies. Leaf clip cages ( $4 \mathrm{~cm}$ diameter) inoculated with $10 \mathrm{P}$. xylostella eggs each, were attached to middle frame leaves. Survival, determined when insects reached the middle of the fourth instar, was calculated as above. The experiment was conducted twice, from 21 July to 3 August (22 cages per line) and from 28 July to 7 August (12 cages per line).

\section{Survival on Leaf Disks in the Laboratory}

Leaf disks ( $3 \mathrm{~cm}$ diameter) were cut from middle frame leaves in the 11 June planting. Within 20 min of cutting, the disks were placed, with a disk of moistened filter paper, in $1230-\mathrm{ml}$ plastic cups per line, and each cup was inoculated with $10 \mathrm{P}$. xylostella eggs about to hatch. At 24 and $48 \mathrm{~h}$, a fresh disk was added to each cup. Survival at the end of $72 \mathrm{~h}$ was determined. The experiment was repeated three times, starting on 17,20 , and 25 July.

\section{Survival on Diets Supplemented with Leaf Extracts}

One hundred grams of leaf tissue were removed from the middle frame leaves of four plants from each cabbage genotype. In the field, immediately after cutting, leaf samples were plunged into boiling $\left(70^{\circ} \mathrm{C}\right)$ ethanol, to minimize enzymic activity, and extracted for $15 \mathrm{~min}$. In the laboratory, the boiled leaf material and ethanol were homogenized in a blender and strained through glass wool. The filtrate was concentrated in a rotary evaporator under reduced pressure. The residue was reextracted with hexane and then water, to produce nonpolar and polar fractions. Filtered polar fractions were concentrated under reduced pressure and added to the standard artificial diet (Biever \& Boldt 1971) at a rate of $4 \mathrm{~g}$ leaf equivalent (LE) per gram of diet. Nonpolar fractions were mixed with cellulose granules and evaporated, with agitation, to dryness. Granular cellulose is an ingredient in the standard diet. The coated cellulose was added to diet to produce a concentration of $4 \mathrm{~g} \mathrm{LE}$ of nonpolar fraction per gram of diet. Control diets contained water or uncoated cellulose in place of the extract fractions. Cups $(30 \mathrm{ml})$ with diet were inoculated with 10 to 20 eggs (depending on the experiment), and survival was determined at fourth instar. This test was repeated five times using nonpolar extracts and seven times using polar extracts for a total of 276 and 388 observations, respectively. The percentage of larvae surviving was adjusted using the formula

$$
\begin{aligned}
& \text { Adjusted \% survival } \\
& \qquad=\left[1-\left(\frac{-\% \text { survival control }}{\% \text { survival treatment }}\right)\right] \times 100
\end{aligned}
$$

Adjusted data from all diet experiments for each extract type were then combined for statistical analysis.

\section{Behavioral Studies}

Preference Test with Fourth Instars. Plants were transplanted in adjacent pairs representing all 10 possible pairwise combinations of the five cabbage genotypes. This was accomplished in the general planting by adding an additional plant to the four central rows in each block, one for each of the four lines to be compared with the line of that specific block. Each of the 10 resulting pairwise combinations was replicated six times. The pairs were planted $30 \mathrm{~cm}$ apart so that the foliage from the plants in the pair could be brought into contact without injuring the plants. Cylindrical cages (3.0 $\mathrm{cm}$ long by $1.5 \mathrm{~cm}$ diameter) with open ends fitted with foam gaskets were attached with one end on each of the plants in a pair. The cages were positioned so that they were horizontal. Larvae were introduced into these cages through a port equidistant from both ends. Larvae could move between the two leaves and feed on the exposed leaf surfaces. Plastic disks prevented larvae from escaping if they chewed through the leaf. Ten fourth instars were placed in these cages, and after $2 \mathrm{~h}$, 
Table 1. Percentage of $P$. xylostella larvae surviving to fourth instar on five cabbage genotypes

\begin{tabular}{|c|c|c|c|c|c|c|}
\hline \multirow{2}{*}{$\begin{array}{l}\text { Inocula- } \\
\text { tion date }\end{array}$} & \multirow{2}{*}{$n$} & \multirow{2}{*}{$\begin{array}{c}\text { Check } \\
\text { 'Round-Up' }\end{array}$} & \multicolumn{4}{|c|}{ Test lines } \\
\hline & & & 2506 & 2503 & 2535 & 2518 (glossy) \\
\hline \multicolumn{7}{|c|}{ Whole-plant inoculations } \\
\hline $\begin{array}{l}24 \text { July } \\
17 \text { Aug. }\end{array}$ & $\begin{array}{l}9 \\
9\end{array}$ & $\begin{array}{l}60.30 \pm 11.60 \mathrm{a} \\
16.00 \pm 2.04 \mathrm{a}\end{array}$ & $\begin{array}{l}61.62 \pm 3.56 \mathrm{a} \\
14.50 \pm 1.92 \mathrm{a}\end{array}$ & $\begin{array}{l}42.88 \pm 6.14 a b \\
14.82 \pm 2.12 a\end{array}$ & $\begin{array}{r}30.22 \pm 3.56 b \\
6.32 \pm 0.68 b\end{array}$ & $\begin{array}{l}0.22 \pm 0.15 c \\
0.16 \pm 0.18 c\end{array}$ \\
\hline \multicolumn{7}{|l|}{ Leaf cages } \\
\hline $\begin{array}{l}3 \text { Aug. } \\
7 \text { Aug. }\end{array}$ & $\begin{array}{l}22 \\
12\end{array}$ & $\begin{array}{l}35.0 \pm 7.8 \mathrm{a} \\
56.7 \pm 5.4 \mathrm{a}\end{array}$ & $\begin{array}{l}36.6 \pm 9.9 \mathrm{a} \\
39.2 \pm 6.6 \mathrm{ab}\end{array}$ & $\begin{array}{l}13.3 \pm 4.5 b \\
32.5 \pm 5.8 b\end{array}$ & $\begin{array}{l}16.6 \pm 6.4 b \\
37.5 \pm 9.5 b\end{array}$ & $\begin{array}{l}0.8 \pm 0.9 c \\
0.0 \pm 0.0 c\end{array}$ \\
\hline
\end{tabular}

Means ( \pm SE) in each row with the same letter are nat significantly different $(\alpha=0.05 ; \mathrm{LSD})$. ANOVA-whole-plant: $\mathrm{df}=4,37 ; P$ $=0.0001 ; 24 \mathrm{July}, F=13.63 ; 17 \mathrm{Aug} ., F=17.55$. Leaf cages: 3 Aug., $F=6.13 ; \mathrm{df}=4,84 ; P=0.0002 ; 7$ Aug., $F=10.08 ; \mathrm{df}=4,44$; $P=0.0001$. Data were transformed to arcsine $\sqrt{x}$ before analysis.

their positions relative to the two leaves were recorded. The middle of each cage was marked and a larva's presence on one side of the line was interpreted as a preference for the leaf clipped to that side of the cage. In addition, the amount of feeding, measured as $\mathrm{mm}^{2}$ leaf tissue removed from the exposed leaf surface in the cage, was recorded after $24 \mathrm{~h}$. Differences in larval location preference in each comparison were evaluated with $x^{2}$. Differences in amount of leaf tissue removed in each comparison were compared with the sign test (Sokal \& Rohlf 1981).

Preference Test with Neonates. Another test was designed to detect discrimination among plant lines by neonate larvae. Five 3-cm disks, one from each line, were cut from plants in the field, immediately brought to the laboratory, and arranged randomly in a circle on a piece of Parafilm in a plastic box. Thirty eggs, about to hatch, were placed in the center of the circle. The disks overlapped slightly so that dispersing larvae could not leave the circle without encountering a disk. Forty-eight hours after the eggs hatched, the number of larvae and the number of mines on each of the disks were counted. A single experiment consisted of 12 replicates, and the experiment was repeated three times.

Neonate Dispersal in the Field. Dispersal rates of larvae on all five genotypes were measured by placing 10 neonates on a middle frame leaf and determining the number remaining within a 10 $\mathrm{cm}$-diameter circle, centered at the point of release, after every $5 \mathrm{~min}$ for $1 \mathrm{~h}$ or until all larvae had left the circle. The percentage of larvae leaving the circle per minute was calculated from these data. Six replicates were conducted for each cab- bage genotype. Dispersal rates were compared using Fisher's least significant different test (LSD) (Sokal \& Rohlf 1981).

Unless otherwise indicated, data were analyzed with analysis of variance using the general linear models procedure (SAS Institute 1985). Means for cabbage lines were compared using Fisher's protected least significance test, or comparisons were made using Student's $t$ test. When necessary to stabilize variances, data were transformed to arcsine $\sqrt{x}$ before analysis, as noted in tables.

\section{Results}

\section{Larval Survival on Plants in the Field}

Whole-Plant Inoculations. Survival to fourth instar was lower on lines 2535 and 2518 than on 'Round-Up' in both experiments (Table 1). Survival on 2506 and 2503 was not significantly different from 'Round-Up.' Overall survival was low in the second inoculation due to a period of cold, rainy weather during the latter half of August.

The number of mines per plant $72 \mathrm{~h}$ after hatch followed the same trend as survival to fourth instar. Mean number of mines was $46.6 \pm 6.0$ on 'RoundUp, $59.8 \pm 6.7$ on $2506,15.6 \pm 4.7$ on $2503,13.0$ \pm 3.9 on 2535 , and $0.0 \pm 0.0$ on 2518 . The mean number of mines on 2503, 2535, and 2518 differed significantly from 'Round-Up' and 2506 ( $P=$ $0.0001)$. Number of mines on 2518 differed significantly from all other lines $(P=0.0001)$ (Student's $t$ test).

Cage Studies. As in the whole-plant inoculations, the glossy line 2518 severely reduced larval survival, survival on 2535 was 50 to $60 \%$ of 'Round-

Table 2. Percentage of $P$. xylostella surviving to fourth instar on artificial diet treated with polar and nonpolar extracts of five cabbage genotypes

\begin{tabular}{|c|c|c|c|c|c|}
\hline \multirow{2}{*}{ Extract } & \multirow{2}{*}{$\frac{\text { Check }}{\text { 'Round-Up' }}$} & \multicolumn{4}{|c|}{ Test lines } \\
\hline & & 2506 & 2503 & 2535 & 2518 (glossy) \\
\hline $\begin{array}{l}\text { Polar } \\
\text { Nonpolar }\end{array}$ & $\begin{array}{r}94.2 \pm 4.2 \mathrm{a} \\
106.6 \pm 4.5 \mathrm{a}\end{array}$ & $\begin{aligned} 84.6 & \pm 5.6 \mathrm{abc} \\
100.6 & \pm 5.1 \mathrm{a}\end{aligned}$ & $\begin{array}{r}76.3 \pm 4.0 c \\
117.3 \pm 9.2 a\end{array}$ & $\begin{aligned} 80.2 & \pm 4.4 \mathrm{bc} \\
101.5 & \pm 5.7 \mathrm{a}\end{aligned}$ & $\begin{aligned} 93.1 & \pm 4.1 \mathrm{ab} \\
106.3 & \pm 4.5 \mathrm{a}\end{aligned}$ \\
\hline
\end{tabular}

Means $( \pm S E)$ in the same row with the same letter are not significantly different $(\alpha=0.05 ;$ LSD). ANOVA, polar diets $n=388$ (F $=3.32 ; \mathrm{df}=4,377 ; P=0.01) ;$ nonpolar diets $n=276(F=1.13 ; \mathrm{df}=4,265 ; P=0.344)$. Data were transformed to arcsine $\sqrt{x}$ before analysis. 
Table 3. Mean proportion of fourth instar P. xylostella located near each of two cabbage genotypes in pairwise choice cage and proportion of total feeding occurring on each genotype after 24 h

\begin{tabular}{llc}
\hline \multicolumn{1}{c}{ Comparison } & Location & Feeding \\
\hline 2518:'Round-Up' & $0.490: 0.510$ & $0.428: 0.571$ \\
2535:'Round-Up' & $0.475: 0.525$ & $0.333: 0.666$ \\
2506:'Round-Up' & $0.473: 0.526^{*}$ & $0.736: 0.263$ \\
2503: 'Round-Up' & $0.520: 0.479$ & $0.333: 0.666$ \\
$2518: 2535$ & $0.384: 0.615$ & $0.529: 0.471$ \\
$2518: 2506$ & $0.461: 0.538$ & $0.636: 0.363$ \\
$2518: 2503$ & $0.513: 0.486$ & $0.454: 0.545$ \\
$2535: 2506$ & $0.666: 0.333$ & $0.375: 0.625$ \\
$2535: 2503$ & $0.571: 0.429$ & $0.588: 0.411^{*}$ \\
$2506: 2503$ & $0.636: 0.367$ & $0.400: 0.600^{*}$ \\
\hline
\end{tabular}

*, proportions significantly different at $P \leq 0.05$. For larval location, numbers of larvae in each side of all cages for each comparison were analyzed using $\chi^{2}$ analysis. For feeding, in each comparison, means of proportion of total consumed in a cage, for each variety, were compared with the sign test. $n=6$ for all comparisons.

Up, and survival on 2506 was not different from 'Round-Up' (Table 1). In addition, survival on 2503 was also reduced to approximately $50 \%$ of 'RoundUp.'

Survival on Leaf Disks in the Laboratory. Survival was greater on leaf disks than on whole plants, and differed less among the cabbage lines than on the whole plants in the field. Percentage of larvae surviving on disks was $53.0 \pm 6.3$ on 'Round-Up,' $55.5 \pm 6.6$ on $2506,39.7 \pm 7.0$ on $2503,51.3 \pm$ 8.0 on 2535 , and $42.4 \pm 7.5$ on 2518 . The ANOVA $F(2.43)$ for the test was marginally significant $(P$ $=0.0492$ ). Survival on leaf disks of highly resistant 2518 was not significantly different from 'RoundUp' or the normal bloom resistant lines (LSD; $\alpha=$ 0.05 ).

\section{Survival on Diets Supplemented with Leaf Extracts}

Significant reduction in survival occurred on artificial diet supplemented with polar extracts of 2503 and 2535 , relative to diet treated with 'RoundUp' extracts (Table 2). Survival on diet treated with extract from 2506 and glossy 2518 was not different from that on 'Round-Up'-extract treated diet. No significant differences occurred among diets supplemented with nonpolar extracts. In general, survival on nonpolar diets was enhanced relative to pure diet controls (adjusted survival $>100 \%$ ).

\section{Behavioral Studies}

Preference Test with Fourth Instars. Preference of fourth instars among the cabbage genotypes in the pairwise choice cages (Table 3) does not reflect levels of resistance in the lines (Table 1). In only one comparison, 2506 compared with 'Round-Up,' was the proportion of larvae on one cabbage type significantly greater than the other in a pair. Proportions of larvae preferring lines in each comparison cannot be used to construct a consistent preference hierarchy for the cabbage types. The proportion of leaf tissue removed was significantly different in two comparisons, 2535 compared with 2503 and 2506 compared with 2503. As with larval orientation preference, however, it is not possible to construct a consistent feeding preference hierarchy, and these data do not reflect resistance levels observed in the field tests.

Preference Test with Neonates. Larvae showed no preference among the lines in this test, based on their distributions on the disks after $48 \mathrm{~h}$ (Table 4). However, the mean number of mines in the disks was significantly higher on glossy 2518 than the other lines. Ranks of the mean number of mines for all the lines were opposite those for number of mines on inoculated plants in the field tests.

Neonate Dispersal in the Field. The percentage of larvae leaving the $10-\mathrm{cm}$ diameter area in $1 \mathrm{~min}$ did not differ among the normal bloom lines and ranged from $0.6 \pm 0.1 \%$ on 'Round-Up' to $1.0 \pm$ $0.2 \%$ on 2503 . The proportion leaving 2518 , however, was $2.1 \pm 0.6 \%$, which was significantly greater $(\alpha=0.05$; LSD) than any of the other lines.

\section{Diseussion}

The resistance to $P$. xylostella in normal bloom lines as well as the glossy 2518 is largely due to reduced larval survival. Differences in larval survival (Table 1) reflect the previously observed differences in damage among the test lines. The mine counts $72 \mathrm{~h}$ after egg hatch indicate that the resistance affects larvae during the first two instars, the only developmental stages that produce mines (Salinas 1984). Therefore resistance in normal bloom 2535 and 2503 is due to reduced survival of early instars as is the case on glossy resistant genotypes (Lin et al. 1983).

Reduced survival on extract-supplemented diet suggests that the resistance in 2503 and 2535 is at

Table 4. Number of larvae and mines per leaf disk of five cabbage genotypes exposed for $48 \mathrm{~h}$, in a single arena, to neonate $P$. xylostella

\begin{tabular}{|c|c|c|c|c|c|}
\hline & \multirow{2}{*}{$\begin{array}{c}\text { Check } \\
\text { 'Round-Up' }\end{array}$} & \multicolumn{4}{|c|}{ Test lines } \\
\hline & & 2506 & 2503 & 2535 & 2518 (glossy) \\
\hline $\begin{array}{l}\text { Larvae/disk } \\
\text { Mines/disk }\end{array}$ & $\begin{array}{l}2.46 \pm 0.30 \mathrm{a} \\
5.31 \pm 0.67 \mathrm{~b}\end{array}$ & $\begin{array}{l}2.86 \pm 0.53 \mathrm{a} \\
6.39 \pm 1.30 \mathrm{~b}\end{array}$ & $\begin{array}{l}2.77 \pm 0.53 \mathrm{a} \\
7.37 \pm 1.30 \mathrm{~b}\end{array}$ & $\begin{array}{l}2.42 \pm 0.60 \mathrm{a} \\
7.39 \pm 1.30 \mathrm{~b}\end{array}$ & $\begin{array}{r}3.09 \pm 0.39 a \\
13.60 \pm 1.99 a\end{array}$ \\
\hline
\end{tabular}

Means $( \pm S E)$ in the same row with the same letter are not significantly different $(\alpha=0.05 ;$ LSD). $n=36$. ANOVA, larvae $(F=$ $0.41 ; \mathrm{df}=4,170 ; P=0.8403)$; mines $(F=6.29 ; \mathrm{df}=4,170 ; P=0.0001)$. 
least in part chemically based. The active compounds, which are polar and extractable in ethanol, may act as physiological toxins, thus causing classic antibiosis, or as antifeedants that reduce larval feeding and survival. Further work will be required to determine this.

Although 2518 was extremely resistant in the field, extracts from this line had no activity in diet. Thus the mechanisms that produced reduced larval survival on 2518 are distinct from those of 2503 and 2535. The higher dispersal rate of neonate $P$. xylostella on 2518 suggests larval nonpreference. Failure of larvae to accept the plants could produce the observed high mortality by leading to protracted searching behaviors, reduced larval feeding, and increased exposure of the insects to desiccation, other environmental stresses, and predation. Such a mechanism would not very strongly affect larvae confined to leaf disks in the controlled environment of the laboratory, and this could account for the relatively high survival of larvae on leaf disks of 2518 and the resistance source PI 234599, as reported by Lin et al. (1983). The greater number of mines on 2518 in the choice experiment (Table 4 ) is difficult to explain, because larvae do not mine on this line in the field. This experiment placed larvae in a very different setting from the no-choice situation faced by neonates in the field, which may account for the inconsistency. Nevertheless, unlike fourth instars (Table 3), neonates demonstrated a behavioral discrimination among the lines. This is consistent with our hypothesis of a behavioral basis for the resistance, which is expressed against first instars but not fourth instars.

The results of these experiments indicate that two types of resistance occur in the tested Geneva breeding lines: (1) antibiosis or nonpreference caused, at least in part, by polar ethanol-extractable compounds in normal bloom lines, 2503 and 2535; and (2) unidentified factors in the glossy line, 2518. Resistance in the glossy line may result from neonate nonpreference.

\section{Acknowledgment}

We thank W. T. Wilsey, K. Simpson, B. Burgess, and B. Cooley for assistance in the field and laboratory. D.
Pimentel, J. A. A. Renwick, J. Steffens, W. Tingey, and S. Baker-Carr reviewed earlier drafts. Incorporation of the suggestions of R. F. Chapman and several anonymous reviewers greatly improved the manuscript. The research was supported in part by the N.Y. Cabbage Research Association and an A. W. Mellon Student Research Grant to S.D.E.

\section{References Cited}

Andaloro, J. T., K. B. Rose, A. M. Shelton, C. W. Hoy \& R. F. Becker. 1983. Cabbage growth stages. New York's Food and Life Sciences Bulletin 101, Cornell University, Agricultural Experiment Station, Ithaca, N.Y.

Biever, K. D. \& P. E. Boldt. 1971. Continuous laboratory rearing of the diamondback moth and related biological data. Ann. Entomol. Soc. Am. 64: 651-655.

Dickson, M. H. \& C. J. Eckenrode. 1980. Breeding for resistance in cabbage and cauliflower to cabbage looper, imported cabbageworm, and diamondback moth. J. Am. Soc. Hortic. Sci. 105: 782-785.

Lin, J., C. J. Eckenrode \& M. H. Dickson. 1983. Variation in Brassica oleracea resistance to diamondback moth (Lepidoptera: Plutellidae). J. Econ. Entomol. 76: 1423-1427.

Lin, J., M. H. Dickson \& C. J. Eckenrode. 1984. Resistance of Brassica lines to the diamondback moth (Lepidoptera: Yponomeutidae) in the field, and inheritance of resistance. J. Econ. Entomol. 77: 12931296.

Salinas, P. J. 1984. Studies on the behavior of the larvae of Plutella xylostella (Linnaeus) (Lepidoptera: Plutellidae), a world pest of cruciferous crops. Normal and spacing behavior. Turrialba 34: 77-84.

SAS Institute. 1985. SAS user's guide: statistics. SAS Institute, Cary, N.C.

Shelton, A. M., C. W. Hoy, R. C. North, M. H. Dickson, \& J. Barnard. 1988. Analysis of resistance in cabbage varieties to damage by Lepidoptera and Thysanoptera. J. Econ. Entomol. 81: 634-640.

Sokal, R. R., F. J. Rohlf. 1981. Biometry. Freeman, San Francisco.

Received for publication 15 February 1989; accepted 19 March 1990. 